\title{
The Impact of the Corona Crisis On the Obligations of the Tenant
}

\author{
Muhammad Fawaz Sabah \\ Department of Law, Al-Maarif University College, Anbar, Iraq \\ mohammedalaloosy210@gmail.com
}

\begin{abstract}
:
The lease contract is one of the most common contracts among members of society, and the most important of which is all, and the reason for that is due to the importance this contract entails for its parties: For the lessor, the lease provides him with the opportunity to invest his money in a guaranteed manner that provides him with financial resources without losing the ownership of the leased, and for the lessee in particular Rent arranges a way to use the money at costs much lower than the price of buying it, so the rent makes the benefit of the rent within the reach of those who need it and cannot buy it, such as renting a home or a place of work or anything else that he needs and cannot buy it because he is unable to pay its price or because of his temporary need for the wages. The social structure of any society includes two sects, the lessor and the lessee, and these two sects are linked with each other in a direct legal relationship, which raises some disputes, and perhaps the most important problem facing both parties to the lease contract is the issue of determining the rent, so if the will of the two parties plays an important role in the issue of determining the rent, then this The will may stand helpless if emergency circumstances arise that impede the tenant without fulfilling his obligation to pay the rent and at the same time push the lessor to ensure that the rent is collected on the basis of which the contract is obligatory $\mathrm{N}$ parties. Because of the spread of the Corona epidemic, which was classified by the World Health Organization as a global epidemic, and as a result, a state of curfew was declared throughout Iraq, which led to the failure to enable the tenant to benefit from the wages, and in light of this the Committee considered Diwaniya No. (55) for the year / 2020 (The period of the Corona virus crisis is a force majeure for all projects and contracts, starting from 2/20/2020 until the Ministry of Health announces the end of the Corona epidemic). Based on these circumstances, there are questions that require a precise legal answer: Will the lease contracts expire by the rule of law if the tenant proves that paying the rent has become impossible? Is this spillage in the interest of the tenant under these circumstances? Can the judge interfere in restoring the contractual balance between the two parties? And does the judge's intervention contradict the obligation of the contract derived from the principle of the contract, the Shari'a of the contractors? What are the aspects that the judge must take into account before weighing the two parties? Therefore, we will try to answer all these questions through this research.
\end{abstract}

Keywords: Crisis; Effect; Tenant; Contract; Iraqi Civil Law. Crossref doi https://doi.org/10.51345/.v31i1.245.g152 


\section{أثر أزمة كورونا على التزامات المستأجر \\ د. محمد فواز صباح \\ قسم القانون، كلية المعارف الجامعة، الأنبار، العراق \\ mohammedalaloosy210@gmail.com}

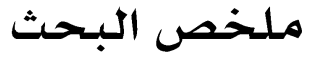

إن عقد الإيجار من أكثر العقود شيوعاً بين افراد المجتمع، وأهمها قاطبة، وسبب ذلك يعود لما يرتبه هذا العقد من أهمية لأطر افه: فبالنسبة للمؤجر، فإن الإيجار يهيئ له فرصة استثلار أمواله بأسلوب مضمون يوفر له موارد مالية دون فقدان ملكية المأجور، وبالنسبة للمستأجر بوجه خاص، يرتب الإيجار أسلويًا للانتفاع بالأموال بتكاليف أقل بكثير من ثمن شرائها، لذلك فان الميكل الاجتماعي لأي بجتمع يشتمل على طائفتين هما المؤجر والمستأجر، وهاتين الطائفتين يرتبطان مع بعضها بعلاقة قانونية مباشرة مما يثير بعض المنازعات، ولعل اهم مشكلة تواجه طرفي عقد الايجار هي مسألة تحديد الأجرة، فاذا كانت ارادة

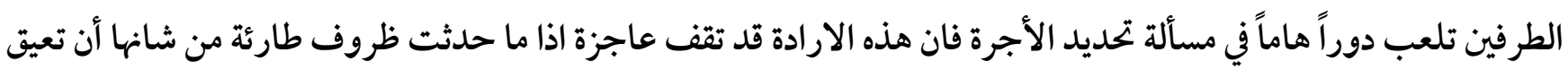
المستأجر دون تنفيذ التزامه بدفع الاجرة وبنفس الوقت تدفع المؤجر المى الحرص على تحصيل الأجرة التي أساسها الزامية العقد ما بين الطرفين. وبسبب انتشار وباء كورونا، وعلى أثر ذلك تم إعلان حالة حظر التجوال في عموم العراق، وبضوء ذلك

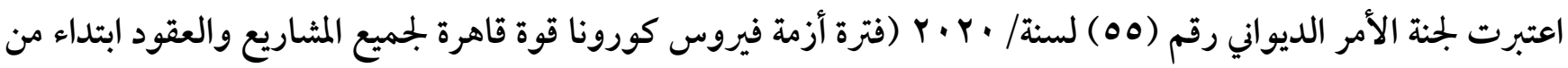

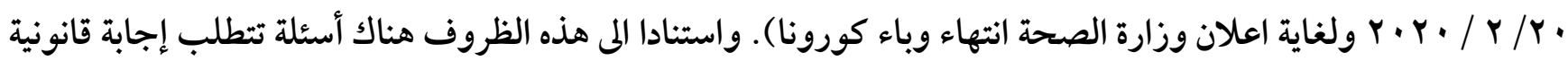
دقيقة: فهل تنفسخ عقود الايجار بحكم القانون إذا اثبت المستأجر بان الوفاء بالأجرة صار مستحيلا؟ وهل هذا الانفساخ من مصلحة المستأجر في ظل هذه الظروف؟ وهل للقاضي أن يتدخل في إعادة التوازن العقدي بين الطرفين؟ وهل تدخل القاضي يتعارض مع الزامية العقد المتأتية من مبدأ العقد شريعة المتعاقدين؟ وما هي الجوانب التي يجب على القاضي مر اعاتها قبل اجراء الموازنة بين الطرفين؟ لذلك سنحاول الإجابة على جميع هذه الأسئلة من خلال هذا البحث.

الكلمات المفتاحية : أزمهة، أثر ، المستأجر، ، عقد، القانون المدني العراقي.

Crossref doi https://doi.org/10.51345/.v31i1.245.g152 


\section{المقدمة}

يُعد عقد الايجار من أهم العقود المسماة وأكثرها تداولاً بين الأشخاص لما يقوم به من دور كبير في تنظيم العلاقة بين المؤجر والمستأجر على مر الزمان، لذلك أولته التشريعات المختلفة أهمية خاصة لخطورة ما يترتب عليه من آثار تتعلق بالأمن الاجتماعي على المجتمع بأسره. فكل فرد في المجتمع يمكن أن يكون طرفاً في علاقة إيجاريه أو أكثر سواء كان مؤجر أو مستأجر، لذلك فهو من أكثر العقود التي تكثر فيها المنازعات أمام المحاكم

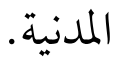
وعقد الإيجار من الناحية الاقتصادية وسيلة لاستثلار المؤجر ما لا يحتاجه من أملاكه للحصول منها على منفعة معينة، ومن الناحية الاجتماعية هو الإطار القانوني الذي يجمع بين طائفتين أحدهما تمثل رأس المال (الملاك)، والأخرى تمثل الطبقة الوسطى من أبناء المجتمع، فهو يحقق التضامن الاجتماعي بين الطائنتين من خلال تبادل المنافع وتوازن الالتزامات، لكن قد تحدث حوادث أو ظروف استثنائية تعيق استمرار ذلك التضامن بسبب اختلال الموازنة العقدية ما بين الطرفين (المؤجر والمستأجر). وفي مثل هكذا ظروف يجب الاستعانة بقواعد العدالة التي تحفف من حدة مبدأ الزامية العقد، سيما إذا علمنا بتقلبات الأوضاع الاقتصادية التي يمر بها العالم أجمع، وذلك يتطلب تفعيل وسائل تعيد للعقد اتزانه بعد ما تأثر بتلك التقلبات، ومن أهم هذه الوسائل إعمال نظرية الظروف الطارئة والقوة القاهرة على التزامات طرفي العقد بغية اعادة التوازن الاقتصادي وتحقيقاً للتضامن الاجتماعي.

\section{إشكالية البـحث:}

تكمن إشكالية البحث في استحقاق المؤجر للأجرة طالما قام بتمكين المستأجر من الانتفاع بالماجور، لكن المستأجر مع هذا التمكين يتعذر عليه الانتفاع بالماجور في ظل الظروف الطارئة التي حلت بالمجتمع بسبب انتشار الوباء سيا إذا تطور الظرف الطارئ المى ظرف قاهر يستحيل معه على المستأجر الإيفاء بالتزامه بدفع الأجرة، وكذلك الالنزامات الأخرى كالمحافظة على المأجور. 


\section{أهميلة البـحث:}

للبحث أهمية كبيرة في ربط فكرة عقود الايجار بالنصوص القانونية إضافة الى الظروف الاقتصادية والاجتماعية التي تحيط دائرة التعاقد سيا ان هذه النصوص جاءت صريحة وواضحة في تحديد التزامات طرفي عقد الاييار، وتأثر هذه الالتزامات بالظروف الطارئة التي تحدث خلال مدة التعاقد، ولتوفير السبل الكفيلة لحلاية الطرف الضعيف في التعاقد وبـا ينسجم مع غايات التشريع.

\section{أهدف البـحث:}

يهدف البحث المى إيجاد موازنة عادلة في الالتزامات العقدية ما بين المؤجر والمستأجر في ظل الظروف الطارئة التي حلت بالمجتمع بسبب انتشار وباء كورونا، ومنع المؤجر من التسلط على المستأجر بفرض التزامات ترهق كاهله أو تجعل أداء التز امه مستحيلاً.

\section{منهجج البـحث:}

سوف يقوم الباحث باستخدام المنهج الوصفي التحليلي من خلال استقر اء الآراء الفقهية والنصوص القانونية الواردة في القانون المدني العراقي، ومحلاًً ما تؤول اليه الظروف الطارئة من مساس بحقوق المستأجر في حال عدم تحقيق موازنة عادلة في الالتزامات ما بين طرفي التعاقد.

\section{المبـحث الأول : التزامـات المستأجر فِ ظل القانون الملدني العراقي} حدد القانون المدني العراقي رقم (40) لسنة/ 1951 التزامات المستأجر في المواد (760- 774) وهي: المحافظة على المأجور واستعاله وفق الغرض الذي أُعد له، ثم دفع الأجرة التي تقابل منفعة الانتفاع بالمأجور والتي تحدد بناء على اتفاق الطرفين، ومن ثم رد المأجور بعد انتهاء مدة العقد وهذا الالتزام ينسجم مع طبيعة عقد الايجار المؤقتة التي لابد لها ان تنتهي يوما ما. وسنتعرض لأحكام هذه الالتزامات بشكل موجز بينما سنقوم بتفصيل التزام المستأجر بدفع الأجرة كونه الالتزام الأهم في العقد ولتعلقه في موضوع البحث. 


\section{المطلب الأول : التزام المستأجر بدفع الأجرة والمحافظة على المأجور}

سنقوم بتقسيم هذا المطلب المى فرعين نتعرض في الأول الى التزام المستأجر بدفع الأجرة، وفي الثاني الى التزام المستأجر بالمحافظة على المأجور وكما يلي:

$$
\text { الفرع الأول: التزام المستأجر بدفع الأجرة }
$$

تعتبر الأجرة من أهم أركان عقد الإيجار وهي التي تضفي عليه صفة عقد الإيجار وبدونها لا يعتبر العقد عقد إيجار، وإنها يتصف بأوصاف أخرى، وتعرف الأجرة بانها المال الذي يلتزم المستأجر تقديمه المى المؤجر مقابل تمكينه من منفعة العين المأجورة، والاجرة هي محل الالتزام بالنسبة للمستأجر ويشترط فيها ما يشترط بالمحل من ان تكون موجودة ومعينة او قابلة للتعيين ومشروعة. وفي ضوء احكام القانون المدني (1) تكون الأجرة غالبا من النقود تدفع مرة واحدة او على شكل أقساط خلال مدد متساوية، ولا يشترط بالأجرة في عقد الايجار ان تكون مبلغاً من النقود وان كان هذا هو الغالب، فيجوز ان تكون الأجرة أموال غير نقدية، فتكون أي مال اخر كان تكون جزء من محصول او قيام بعمل معين او بناء او تحسينات وغير ذلك وهذا ما بينته المادة (736) من القانون المدني العراقي والتي نصت على: (يصح ان تكون الأجرة نقودا كما تصح ان تكون أي مال اخر ). أما عن تحديد الأجرة فإنها في الأصل تخضع لإرادة الطرفين عملا بقاعدة العقد شريعة المتعاقدين وان كل طرف حر بالتصرف بـا يملك من حق له على أمو اله سواء كان المؤجر أو المستأجر، او ان يتفقا على الأسس التي يتم بضوئها تحديد الأجرة(2)، فقد تكون الأجرة نسبة من الربح اليومي او الدخل الشهري، كما يجوز ان يترك الطرفان تحديد الأجرة لشخص ثالث. إلا انه لا يو جد ما يمنع من ترك تحديد الأجرة للعرف السائد، أما إذا لا يوجد مثل هذا العرف ولم يمددها المتعاقدان يتم اللجوء إلى تقدير اجر المثل ولابد من الانتباه إلى أن عدم ذكر الأجرة لا يعني انصراف نية الطرفين إلى عدم تحديد الأجرة أو إهمالها بمعنى عدم استيفائها، لان ذلك سيغير من وصف العقد. وفي حالة عدم اتفاق المتعاقدين على قيمة الأجرة واختلافهم في ذلك فيعد العقد باطلا لتخلف ركن من اركانه. 
الفرع الثاني: التزام المستأجر بالمحافظة على المأجور يتضمن هذا الالتزام أكثر من جانب، حيث يشتمل على نواحي تتعلق باستعمال الشيء المأجور استعمالاً

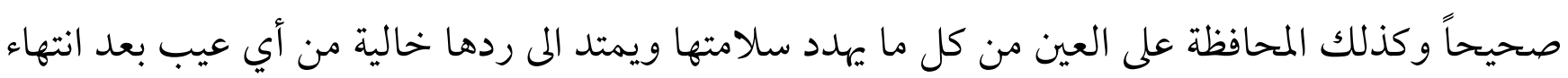
مدة الاجارة لذلك ستتعرض لهذا الالنزام من خلال النقاط التالية: أولا: الالنزام بالعناية بالثيء المأجور: نصت المادة (764) من القانون المدني العراقي على أن: (المأجور أمانة في يد المستأجر)، ويموجب هذا الالتزام يقع على عاتق المستأجر حفظ العين المؤجرة وعدم اهماها وأن يبذل في سبيل ذلك عناية الرجل المعتاد ، فاذا بذل هذه العناية يكون قد أوفى بالتزامه في المحافظة على المأجور، وبمفهوم المخالفة فاذا لم يبذل العناية اللازمة في المحافظة على الشيء الماجور يكون قد أخل بهذا الالتزام، كما

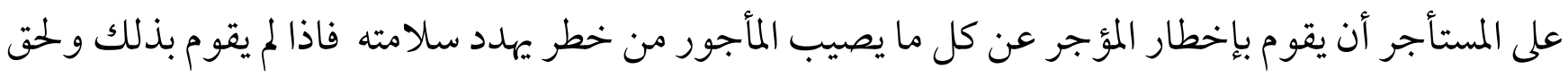
ضرر بالعين المؤجرة فللمؤجر أن يطالب بفسخ العقد مع التعويض أو يطالب المستأجر بإصلاح الضرد (التنفيذ العيني) إذا كان ذلك مككناً. ثانيا: استعحال المأجور: وفق الغرض الذاني ذأُعد له: يجب على المستأجر أن يستعمل المأجور حسب الغرض

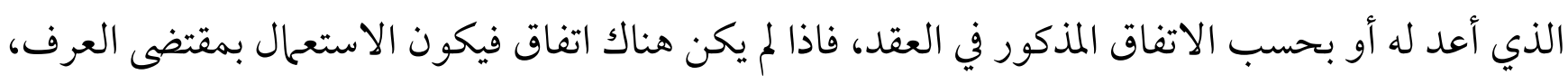

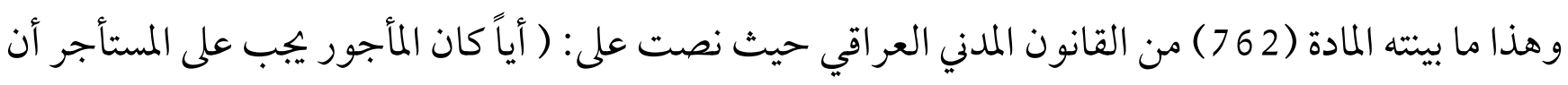

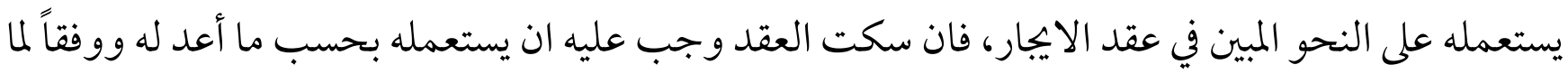
يقتضيه العرف). والحكمة من ذلك هو ابعاد الضرر عن المأجور فاذا انتفى الضرر انتفت معه حكمة التقييد.

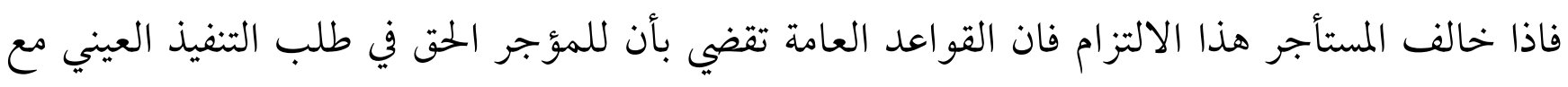
التعويض أو يطالب بفسخ العقد مع التعويض.

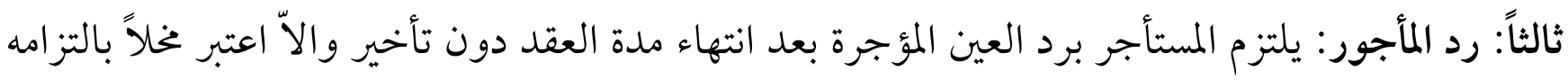
وتترتب عليه المسؤولية حيث يهق للمؤجر طلب التنفيذ العيني وإقامة دعوى قضائية وعلى المحكمة أن تراعي

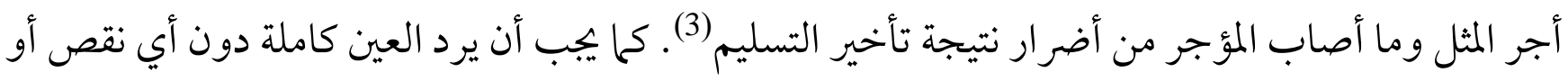


تغيير حيث يجب تسليمها بالحالة التي استلمها في بداية عقد الايجار. أما إذا ردها المستأجر ولكن كانت ناقصة أو تالفة فإنه يلتزم بتعويض المؤجر بالنفقات اللازمة لإعادة العين لحالتها الأولى والتعويض عن المدة التي يحرم

خلالما الانتفاع بالعين واستغلالها مالم يقدم المستأجر دليلا بأن الهلاك يعود لسبب أجنبي لا يد له فيه (4).

\section{المطلب الثاني: أحكام الالتزام بـفع الأجرة}

وجزاء الاخلال بهذا الالتزام ذكرنا في الفرع الأول من المطلب الأول بأن الأجرة هي المال الذي يدفعه المستأجر للمؤجر، وفي هذا المطلب سنتعرض الى أحكام دفع الأجرة وجزاء الإخلال بدفعها، وسنقوم بتقسيم هذا المطلب الى فرعين، نتعرض في الأول الى احكام دفع الأجرة، وفي الثاني

$$
\text { الفر جزاء الاخلال بدفع الأجرة وكما يلي: }
$$

الأجرة ركن في عقد الإيجار وهي أول وأهم ما يلتزم به المستأجر تجاه المؤجر، والأصل أن يتفق المتعاقدان على تحديد الأجرة و موعد دفعها، فاذا اتفق المتعاقدان على قيمة الأجرة يلتزم المستأجر بدفع هذه القيمة بدون زيادة أو نقصان(5)، لكن إذا غفل المتعاقدان تحديد الأجرة أو تعذر اثباتها فيلتزم المستأجر بأجر المثل وهذه ما بينته المادة ( 38 ) من القانون المدني العراقي. ويستحق المؤجر الأجرة طالما قام بتسليم المأجور للمستأجر حتى لو كان الأخير لم ينتفع بالعين انتفاعاً كلياً أو جزئياً، وهذا ما نصت عليه المادة ( 70 ) من القانون المدني العراقي. وعلى المستأجر الالتزام بدفع الأجرة كاملة في مو اعيد استحقاقها، ويجوز تعجيلها أو تأجيلها أو تقسيطها وبهذا الصدد نصت المادة (75 ) من القانون المدني العراقي على: (يصح اشتراط تعجيل الأجرة وتأجيلها وتقسيطها المى أقساط تؤدي في أوقات معينة). وفي حالة قيام نزاع بين المستأجر والمؤجر حول الأجرة يجب على المستأجر الاستمرار بدفع الأجرة إلى أن يفصل في هذا النزاع بحكم قضائي أو يحسم باتفاق الطرفين، وإلا اعتبر المستأجر متخلفاً عن أداء التزامه. 
وإذا اشترط تقسيط الأجرة أو تأخيرها فلا يلتزم بأدائها الاّ في موعدها، وهذا ما أكدته المادة (7 67 ) من القانون المدني العراقي بنصها على: (إذا اشترط تأجيل الأجرة أو تقسيطها، فلا تلزم الأجرة أو الأقساط المتفق عليها الآّ عند حلول الأجل ويلزم المؤجر أن يُسلم المأجور للمستأجر ما دام قد استوفى الحال من الأجرة). وقد يحصل ألا يوجد اتفاق بين المؤجر والمستأجر على موعد دفع الأجرة(6)، ففي هذه الحالة يطبق المبدأ بأن الأجرة لا تدفع الاّ بمقابل المنفعة لذا وجب دفعها مؤخراً أي في نهاية الشهر، فلا تستحق الاّ إذا انتفع المستأجر بالماجور، وهذا ما بينته المادة (68 68 ) من القانون المدني العراقي حيث نصت على: (إذا لم يشترط التعجيل أو التأجيل، فتلزم الأجرة باستيفاء المنفعة أو بالتمكن من استيفائها ولو لم تستوفِ). الفرع الثاني: جزاء اخلال المستأجر بدفع الأجرة في حالة اخلال المستأجر بالتزامه بدفع الأجرة، في هذه الحالة ينهض حق المؤجر بحبس العين المؤجرة لحين الوفاء بالأجرة، كما يحق له طلب فسخ العقد، وهذا ما بينته المادة (66 76) من القانون المدني العراقي حيث نصت على:( ذا اشترط تعجيل الأجرة لزم المستأجر دفعها وقت العقد، وللمؤجر ان يمتنع عن تسليم المأجور للمستأجر حتى يستوفي الأجرة وله أن يطلب فسخ الايجار عند عدم الايفاء من المستأجر ). كما يمق للمؤجر حبس المنقو لات الخاصة بالمستأجر بها يتناسب مع قيمة الأجرة التي لم يوفها، فالمؤجر له حق الامتياز على المنقولات الموجودة في المأجور (7) وحتى ان خرجت هذه المنقولات من المأجور دون علم المؤجر أو بعلمه مع اعتراضه على خروجها، تبقى هذه المنقولات مثقلة بحق الامتياز (المادة/ 1374) من القانون المدني العراقي.

\section{المبحث الثاني : أزمة وباء كورونا ونظريـة الظروف الطارئة} تُعرف الظروف الاستثائية التي تشكل قوة قاهرة هي عبارة عن وقائع مادية صرفه تكون لها آثار سلبية واضحة يمكن رصد ملامحها على المجتمع بشتى معاملاته وعلى العلاقات القانونية بوجه عام والعلاقات التعاقدية بوجه الخصوص، حيث تصاب هذه العلاقات ببعض القصور أو العجز إثر هذه الظروف التي حلت 
بالمجتمع، ما قد يجعل من المستحيل أو على الأقل من الصعب تنفيذ بعض الالتزامات أو يؤخّر تنفيذها. فهل

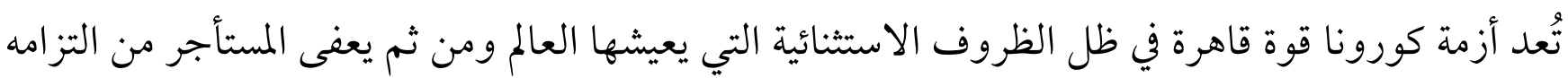
بدفع الايجار (8) في الموعد المحدد سيا إذا تمسك بالسبب الأجنبي الذي يدفع المسؤولية عن صاحبه لأنه خارج عن ارادته. ولغرض تسليط الضوء على هذا الأمر سنقوم بتقسيم هذا المبحث الى المطلبين التاليين:

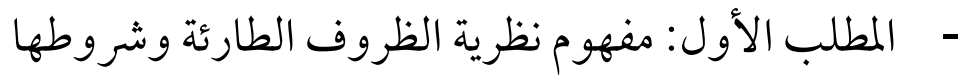
- م المطلب الثاني: أثر نظرية الظروف الطارئة على التزام المستأجر

\section{المطلب الأول : مفهوم نظريـة الظروف الطارئة وشروطها}

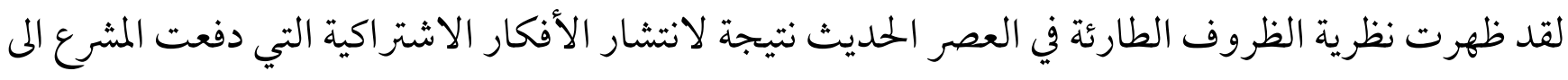
التدخل بالتنظيم في الكثير من العقود ماية للمصلحة العامة أو الطرف الضعيف في العقد، كرد فعل على مبدأ

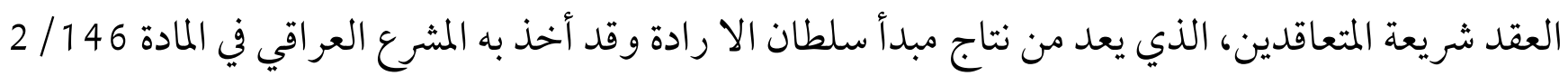
التي نصت على: (اذا طر أت حوادث استثنائية عامة لم يكن في الوسع توقعها وترتب على حدوثها ان تنفيذ

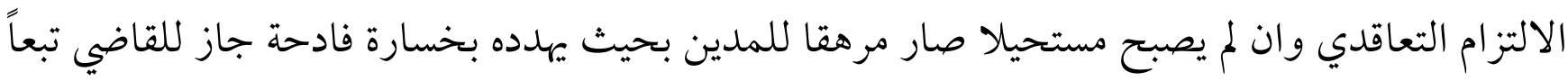
للظروف بعد الموازنة بين مصلحة الطرفين ان تنقص الالتزام المرهق الى الحد المعقول ويقع باطلا كل اتفاق خلاف ذلك)، وقد أشار المشرع المصري(9) لنفس النص في المادة 147/2 من القانون المدني المصري. وسنتعرض الم شروط هذه النظرية في الفروع التالية: الفرع الأول: وقوع حادث استثنائي عام

ويراد بالحادث الاستثنائي أن يكون مما لا يتفق مع السير الطبيعي العادي للأمور، أي يكون بعيدا عار الفه الناس ويعد الحادث استثنائيا إذا ندر وقوعه، وهناك من الحوادث الطارئة ما يعد استثنائيا بمجرد وقوعه، وذلك لندرة وقوعه، كالحرب أو الزلازل أو الوباء، ومنها ما يكثر وقوعه فلا يكون استثنائيا بحيث يؤدي الى ولى

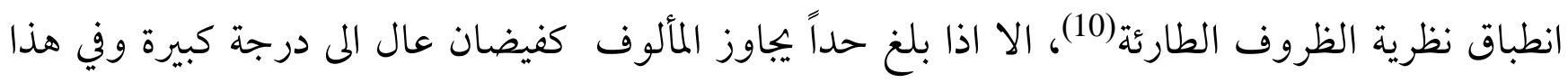


الصدد فقد عدت عحكمة التمييز العراقية ، فيضان سنة/ عهو الذي كان فيضان غير مألوف، وعُّ ظرفاً طارئاً، وكذلك الحو ادث التي رافقت الاعتداء الاسرائيلي سنة 197 . الفرع الثاني: عدم إمكانية توقع الحادث

ومعيار عدم التوقع معيار موضوعي وهو معيار الشخص المعتاد، ويتطلب أن يكون عدم التوقع مطلقاً، فلا يكفي فيه أن يكون غير ممكن التوقع من جانب المدين، وإنها أيضاً يجب أن يكون غير ممكن التوقع من جانب أكثر الناس حيطة وحذراً. ويترتب على ذلك أنه إذا كان الحادث متوقعاً، فإنه لا يعفي من المسؤولية، ومثال ذلك سقوط الثلوج في فصل الشتاء في مدينة معروف عنها حدوث ذلك كل موسم هو أمر متوقع ومن ثمّ لا يُعد قوة قاهرة. الفرع الثالث: أن يكون حادثاً عاماً يستحيل دفعه أن يكون الحادث عاماً: بمعنى هذا ان الحادث لا يخص المدين وحده انما يشمل عامة المجتمع، فاذا كانت الظروف أو الحو ادث تخص المدين وحده أو أفر اد عائلته، كمرضه أو افلاسه أو وفاته فلا يُعفى من المسؤولية . واستحالة دفع الحادث: بمعنى أن الحادث يجب أن يؤدي إلى استحالة تنفيذ الالتزام استحالة مطلقة، فإذا استطاع المدين دفع الحادث أو يتفاداه ولم يفعل، فلا يعفي هذا الحادث المدين من المسؤولية حتى لو كان غير مككن التوقع. الفرع الرابع: أن يكون الالتزام التعاقدي مرهقاً للمدين أن يصبح الالتزام التعاقدي مرهقاً للمدين، و يعد ارهاق المدين من أهم الشروط التي يجب الاعتماد عليها للحكم بأن هناك اختلالاً في التوازن الاقتصادي في العقد، ومن ثم تطبيق احكام نظرية الظروف الطارئة على الو اقعة فالإرهاق هو الذي ينقل نظرية الظروف الطارئة من الميدان النظري الى ميدان التطبيق العملي (11)، وهو أول ما يهتم القاضي بد را سته والتحقق من توفره، وتبرز أهمية شرط الارهاق في انه مها تكن درجة الحوادث الاستثنائية من الخطورة وعدم توقع حدوثها، فإنها تكون عديمة الأثر على العقد مالم ينتج عن حدوثها ارهاق في تنفيذ احد الالتز امات الناشئة عن العقد. 
وهذه الشروط يجب أن تتحقق مجتمعة لا يكفي تحقق بعضها، فاذا تحققت جميعها انطبق وصف الحوادث الطارئة على الملتزم وبالتالي تنتفي عنه المسؤولية القانونية، لأن مسئولية الشخص العقدية يجب أن تتوافر ثلاثة أركان وهي (الخطأ والضرر والرابطة السببية بينها)، فانعدام رابطة السبية بين الخطأ والضرر عندما يكون ناشئاً عن تدخل سبب أجنبي كالقوة القاهرة يمنع توقيع الجزاء التعاقدي على هذا الطرف الذي عجز عن تنفيذ التز امه لهذا الظرف.

\section{المطلب الثاني: أثر نظرية الظروف الطارئة على التزام المستأجر} ان التزام المستأجر بدفع الأجرة ناشئاً عن العقد، أي ان هذا الالتزام يستند على قاعدة "العقد شريعة المتعاقدين" المعروفة على مبدأ أساسه أن ليس لأحد أطراف العقد أن يستقل بإلغاء أو تعديل العقد أو أن يتحلل من التزاماته بطريقة منفردة، وان الالنزامات التي تقررت بمقتضى العقد الذي أبرمه بإرادته الحرة مع الطرف الآخر تكون لها قوة كقوة القانون(12)، كما أنه ليس للقاضي التدخل في تعديل العقد أو الغائه من غير رضا المتعاقدين، إلا أنه إذا حال أمر جعل هذا الالتزام صعب التحقيق لسبب خارج عن إرادة الملتزم به ولا يستطيع تو قعه أو دفعه عنه أياً كان هذا الظرف الطارئ يشكل قوة قاهرة تمنعه من الوفاء بالتز امه جاز للقاضي تطبيق أحكام نظرية الظروف الطارئة على العقد بعد التحقق من الشروط التي يتطلبها القانون ليتولى إعادة التوازن الاقتصادي للعقد عن طريق توزيع العبأ الطارئ على عاتق المتعاقدين أو اعفائه من مما التزم به وامهاله الوقت الكافي لتدارك هذا الالتزام بعد زوال هذا الظرف الاستثنئي (13). ومن اجل تطبيق النظرية على أزمة وباء كورونا سنتعرض لذلك من خلال الفروع التالية: الفرع الأول: التزام المستأجر يقابل المنفعة ان عقد الايجار من عقود المنفعة، حيث تنص المادة ( VYY) من القانون المدني العراقي على: (الإيجار تمليك منفعة معلومة بعوض معلوم لمدة معلومة وبه يلتزم المؤجر بتمكين المستأجر بالانتفاع بالمأجور)(14)، فالمؤجر مُلزم بتمكين المستأجر من الانتفاع بالمأجور وإن الأجرة تقابل المنفعة، فلا تستحق الأجرة الاّ اذا استوفى المستأجر تلك المنفعة، وبسبب انتشار وباء كورونا الذي تم تصنيفه من قبل منظمة الصحة العالمية بانه وباء 
عالمي وعلى أثثر ذلك تم إعلان حظر التجوال في عموم العراق ما أدى الى عدم تمكين المستأجر من الانتفاع بالمأجور، وبذلك انتفت المنفعة بسبب الظروف آنفاً. الفرع الثاني: اعتبار ازمة وباء كورونا ظرفاً طارئاً

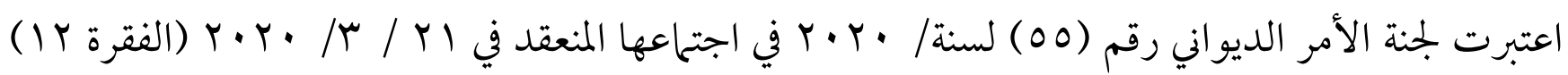
(فترة أزمة فيروس كورونا قوة قاهرة لجميع المشاريع والعقود ابتداء من ·r / r / · · · و ولغاية اعلان وزارة الصحة انتهاء وياء كورونا). واستنادا المى الأمر الديواني أعلاه فان جميع عقود الايجار تنفسخ وبحكم القانون إذا أثبت المستأجر بأن الوفاء بالأجرة أصبح مستحيلاً استناداً للمادة (425) من القانون المدني العراقي التي نصت على: (ينقضي الالتزام إذا أثبت المدين ان الوفاء به أصبح مستحيلاً لسبب أجنبي لا يد له فيه)، اذ اعتبر المشرع العراقي القوة القاهرة صورة من صور السبب الأجنبي (المادة ||YY) مدني عراقي. لكن يجب التمييز بين الاستحالة المطلقة وغير المطلقة، ففي حالة الاستحالة المطلقة ينفسخ العقد بقوة القانون (المادة/ 525 ) مدني عراقي، أما إذا كانت الاستحالة غير مطلقة (نسبية) ففي هذه الحالة لا ينفسخ العقد لكن ينهض دور القضاء لإعادة التوازن العقدي ما بين الطرفين. وفي تقديرنا ان اعتبار هذا الوباء قوة قاهرة بصورة مطلقة لجميع عقود الإيجار غير صحيح، إذ ان انفساخ العقد لاستحالة دفع الأجرة بسبب هذا الوباء يتطلب أن تكون الاستحالة مطلقة والتي لا يستطيع معها المستأجر تسديد الأجرة مطلقا، لكن طالما يستطيع المستأجر الانتفاع بالمأجور ولو بشكل غير تام، فالاستحالة اذاً ليست مطلقة، هذا من جانب. ومن جانب آخر نرى بأنه ليس من مصلحة المستأجر اعتبار عقد الايجار منفسخاً بحكم القانون. لذلك سوف يلجأ المستأجر المى المطالبة بإعادة التوازن الاقتصادي لعقد الايجار استنادا للملمة ( ) ( ) من القانون المدني العراقي. الفرع الثالث: دعوى المستأجر بتطبيق نظرية الظروف الطارئة للمستأجر حق المطالبة بتطبيق نظرية الظروف الطارئة وذلك بانقاص الأجرة خلال فترة الأزمة الى الحد المعقول أو تأخير تنفيذ الالتزام الى ما بعد زوال الظرف الطارئ، لأن تنفيذ المستأجر التزامه بالوفاء بالأجرة 
ليس بالاستحالة المطلقة وانما التنفيذ أصبح مرهقا بحيث يهدده بخسارة فادحة، وللمحكمة سلطة تقديرية في

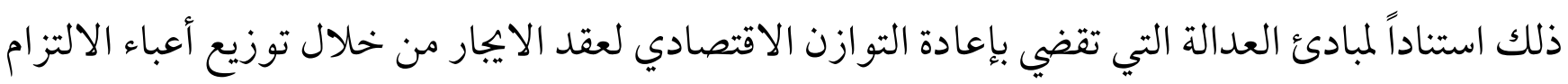

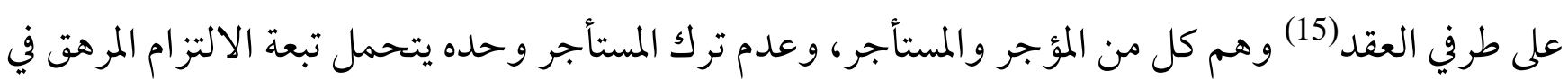
ظل هذه الظروف الطارئة، وهذا ما يوافق قو اعد العدالة الاجتماعية ويتطابق مع المفهوم الحديث للملكية. الفرع الرابع: المفهوم الحديث لحق الملكية أن من خصائص حق الملكية باعتباره حقاً عينياً هو (حق مطلق) (16)، على أنه لا يقصد بذلك أن الملكية حق لا لا تحده حدود، فصفة الاطلاق بهذا المعنى لم تعد تنسجم مع التطورات الفقهية والاجتماعية الحديثة، فما يراد

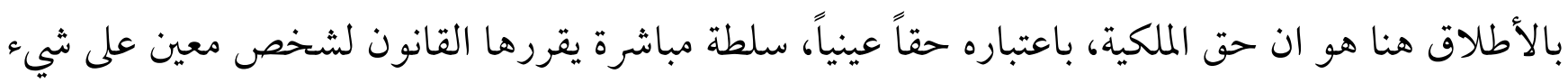

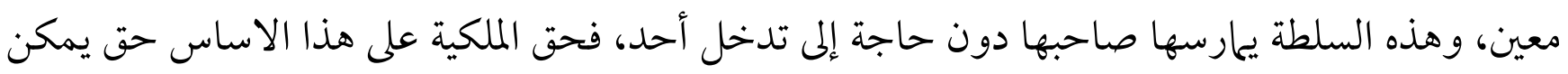
الاحتجاج به قبل الكافة. فالملكية لم تعد حق مطلق، وانما صارت وظيفة اجتماعية تُمارس على نحو يحقق التضامن الاجتماعي وتخضع للحماية القانونية مادامت تؤدي وظيفتها الاجتماعية فاذا أخلت بوظيفتها تدخل القانون ونزع الحماية عنها، وهذا المفهوم يتفق أيضا مع المنظار الإسلامي للملكية الذي يؤكد على وجوب توظيف المال في التعاون والتكافل الاجتماعي، ويتعين على المالك الالتزام التام والكامل بالقيود الشرعية لاستعال المال وتوظيفه

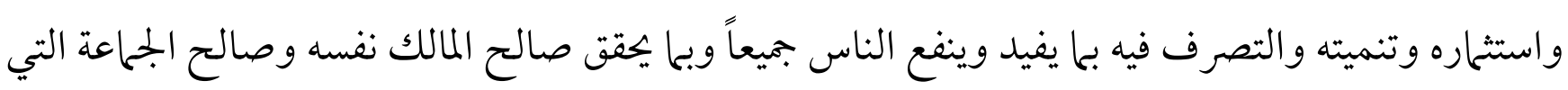
يعيش فيها. وقد أفرزت أزمة وباء كورونا تكافلاً اجتماعياً كبيراً ما بين فئات المجتمع المختلفة وعلى مختلف مجالات الحياة، والعلاقة ما بين المؤجر والمستأجر ليست بمنأى عن ممارسات التكافل لاجتماعي المنشود ما بين المؤجر والمستأجر. 


\section{الخاتهـة:}

من خلال ما تقدم توصل الباحث الم النتائج والتوصيات التالية:

\section{النتائج}

1 - يخظى عقد الايجار بأهمية كبيرة في المجتمع لكثرة تداوله ما بين افراده ولما يحققه من أهمية اقتصادية واجتحاعية على نطاق واسع.

2- تفشي وباء كورونا وما أعقبه من آثار انعكست بشكل كبير على العلاقات التعاقدية ما بين المؤجر و المستأجر التي باتت تختل في حالة عدم النظر بها في ظل انتشار هذا الوباء. 3- تتزاحم في التطبيق نظريتين في ظل انتشار وباء كورونا، الأولى نظرية الظروف الطارئة والثانية القوة القاهرة بسبب تطابق أحكامها، الا انها يختلفان في أمرين، الأمر الأول: ان الظرف الطارئ لا يعجز المدين عن الوفاء بالتزامه كلياً ولكن يكون مرهقاً له، والأمر الثاني: في الظروف الطارئة لا يترتب انفساخ العقد ولكن المحكمة تتدخل لإنقاص الالتزام المرهق المى الحد المعقول لإعادة الموازنة العقدية بين الطرفين. 4- ان نظرية الظروف الطارئة والقوة القاهرة لها الدور البارز في الواقع العملي لأنها تمثل خروجاً ضرورياً تقتضيه قو اعد العدالة للحد من القوة الملزمة للعقد. 5- ان مبدأ العقد شريعة المتعاقدين، لا يقف حائلاً أمام نظرية الظروف الطارئة التي باتت أهم استثناء يرد عليه لغرض إعادة التوازن الاقتصادي ما بين طرفي العقد عن طريق القضاء. 6- ان سلطة القاضي (التقديرية) في تعديل الالتزامات ما بين الطرفين تتمثل بمبدأ إنقاص أو تأخير تنفيذ الالتزام الى الحد الممكن، أو وقف أو فسخ العقد. 


\section{التوصيات}

1 - يوصي الباحث أنه لتطبيق نظريتي الظروف الطارئة والقوة القاهرة يتعين النظر في كل حالة على حدة فيا إذا كان انتشار فيروس كورونا قد أدى الى استحالة تنفيذ الالتزام ومن ثم يكون مصير العقد الفسخ، أم انه جعل الالتزام مرهقاً على المستأجر ويكفي بهذه الحالة بإنقاص القاضي الالتزام الى الحد المعقول. 2- يتعين على المدين (المستأجر) الاثبات أمام المحكمة بأن الاستحالة مطلقة أم نسبية، ففي الحالة الأولى ينفسخ العقد بحكم القانون، وفي الحالة الثاني من الممكن إنقاص أو تأخير تنفيذ الالتزام. 3 - يمكن للمدين أن ينفي عن نفسه المسؤولية المدنية التي يستند عليها الطرف الآخر، وعليه يقع عبء الاثبات بأن الضرر لا ينسب اليه ولا دخل له في وقوعه وان العلاقة السببية تنتفي بين الضرر والنتيجة بسب السبب الأجنبي.

4- ان أثر الظروف الطارئة لا يعفي المستأجر من تنفيذ التزامه بشكل مطلق بل يوقف تنفيذه حتى يزول السبب الأجنبي أو يخفف من أعبائه، فيكون الالتزام موقوفاً على زوال سبب الوقف. 5 - على القاضي ممارسة سلطته التقديرية بضوء المامه بالظروف المحيطة بانتشار وباء كورونا من إجراءات حكومية وتحديد المناطق الموبوءة الأكثر ضرراً وكذلك تقدير حالة المستأجر من خلال معرفة جميع الظروف التي ألمت به قبل الشروع في الحكم من أجل تحقيق موازنة عادلة ما بين الطرفين.

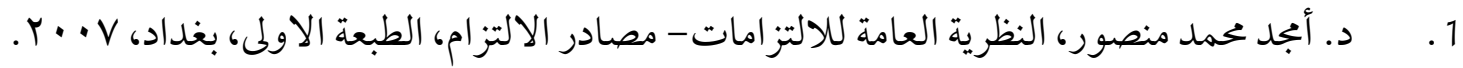
2. د. جعفر الفضلي، الوجيز في العقود المدنية، ط4، دار العاتك، القاهرة، 2009. 3. د. حنفي محمد غالي، نظرية الظروف الطارئة وعمل الأمير ومدى انطباقها على عقود ببع أملاك الحكومة، مجلة ادارة قضايا الحكومة، العدد الثالث، السنة الثانية، 1901. 4. د. حسين عامر، القوة الملزمة للعقد، القاهرة، 99 1. 5. 
6 6 رمضان أبو السعود، دروس في العقود المسماة، عقد الايجار في القانون المصري واللبناني، الدار الجامعية، 1986. 7. د. سعيد مبارك و د. طه الملا حويش، و د. صاحب عبيد الفتلاوي، الموجز في العقود المسماة، المكتبة القانونية، بغداد،

8. د. عبد الرزاق احمد السنهوري، مصادر الحق في الفقه الإسلامي - دراسة مقارنة بالفقه الغربي، الجزء السادس)

$$
\text { الطبعة الثانية الجميدة، منشورات الحلبي الحقوقية، بيروت، } 1991 .
$$

9 9. د. عبد المجيد الحكيم، الموجز في شرح القانون المدني - مصادر الالتزامات، الجزء الأول، مطبعة العاني، بغداد،

10. محمد طه البشير وغني حسون طه، الحقوق العينية، مطبعة وزارة التعليم العالي والبحث العلمي، بدون سنة نشر. 11. د. محمد لبيب أبو شنب، مصادر الالتزام، القاهرة، 19V7-1977.

12. د. منذر الفضل، النظرية العامة للالتزامات في القانون المدني - مصادر الالتزام، الجزء الأول، الطبعة الاولى، دار

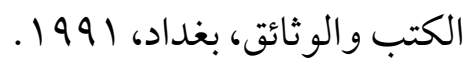

13 ـ د. عصمت عبد المجيد بكر، نظرية العقد في القوانين المدنية العربية، دار الكتب العلمية، بيروت، 197.

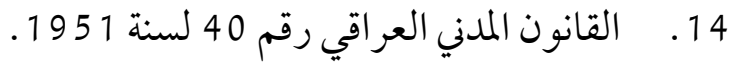

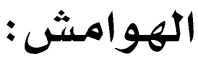

(1) د. جعفر الفضلي، الوجيز في العقود المدنية، ط4، دار العاتك، القاهرة، 2009، ص255. (2) د. سعيد مبارك و د. طه الملا حويش، و د. صاحب عبيد الفتلاوي، الموجز في العقود المسماة، المكتبة القانونية، بغداد، 2018،

$$
\begin{aligned}
& \text { ص } 236 . \\
& \text { (3) د. سعيد مبارك وآخرون، الموجز في العقود المسماة، المرجع السابق، ص238. } \\
& \text { (4) د. جعفر الفضلي، الوجيز في العقود المدنية، مرجع سابق، ص260. }
\end{aligned}
$$

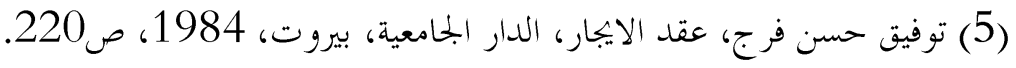

(6) رمضان أبو السعود، دروس في العقود المسماة، عقد الايجار في القانون المصري واللبناني، الدار الجامعية، 1986، ص183.

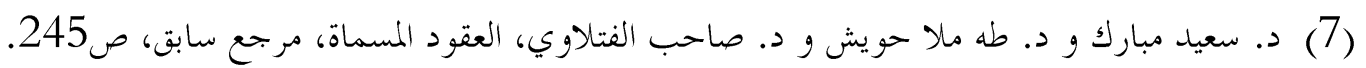

(8) د. منذر الفضل، النظرية العامة للالتزامات في القانون المدني - مصادر الالتزام، الجزء الأول، الطبعة الاولى، دار الكتب والوثائق،

$$
\text { بغداد، الم }
$$




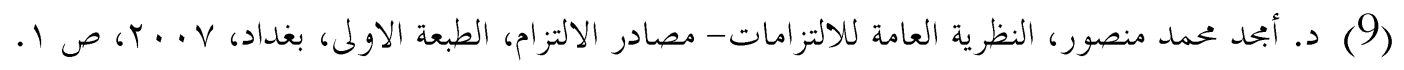
(10) د. حنفي محمد غالي، نظرية الظروف الطارئة وعمل الأمىر ومدى انطباقها على عقود ببع أملاك الحكومة، بحلة ادارة قضايا

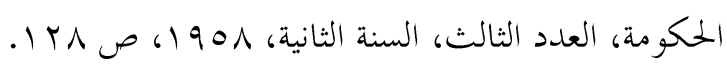

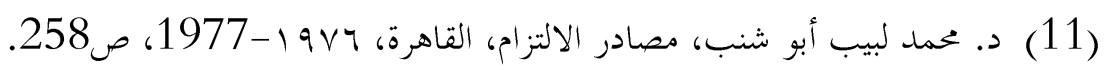

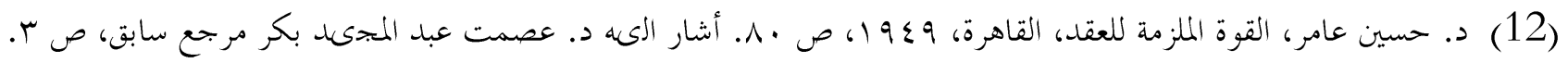
(13) د. عبد الرزاق احمد السنهوري، مصادر الحق في الفقه الإسلامي - دراسة مقارنة بالفقه الغربي، الجزء السادس) الطبعة الثانية

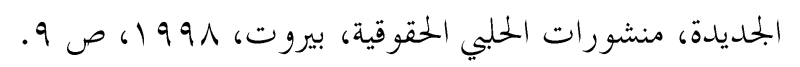
(14) المادة (277)، القانون المدني العراقي.

(15) د. عبد المجىى الحكيم، الموجز في شرح القانون المدني - مصادر الالتزامات، الجزء الأول، مطبعة العاني، بغداد، 1974، ص 400 (16) محمد طه البشير وغني حسون طه، الحقوق العينية، مطبعة وزارة التعليم العالي والبحث العلمي، بلدون سنة نشر، ص43. 